Article

\title{
Self-assembly Synthesis of Molecularly Imprinted Polymers for the Ultrasensitive Electrochemical Determination of Testosterone
}

\author{
Kai-Hsi Liu ${ }^{1,2}$, Danny O’Hare ${ }^{3}$, James L. Thomas ${ }^{4}$, Han-Zhang Guo ${ }^{2}$, Chien-Hsin Yang ${ }^{2, *}$ and \\ Mei-Hwa Lee ${ }^{5, *}$ \\ 1 Department of Internal Medicine, Division of Cardiology, Zuoying Branch of Kaohsiung Armed Forces \\ General Hospital, Kaohsiung 813, Taiwan; liukaihsi@gmail.com \\ 2 Department of Chemical and Materials Engineering, National University of Kaohsiung, Kaohsiung 81148, \\ Taiwan; pzps0964431@gmail.com \\ 3 Department of Bioengineering, Imperial College, London SW7 2BY, UK; d.ohare@imperial.ac.uk \\ 4 Department of Physics and Astronomy, University of New Mexico, Albuquerque, NM 87131, USA; \\ jthomas@unm.edu \\ 5 Department of Materials Science and Engineering, I-Shou University, Kaohsiung 84001, Taiwan \\ * Correspondence: yangch@nuk.edu.tw (C.-H.Y.); meihwalee@ntu.edu.tw (M.-H.L.)
}

Received: 30 January 2020; Accepted: 25 February 2020; Published: 27 February 2020

\begin{abstract}
Molecularly imprinted polymers (MIPs) can often bind target molecules with high selectivity and specificity. When used as MIPs, conductive polymers may have unique binding capabilities; they often contain aromatic rings and functional groups, which can undergo $\pi-\pi$ and hydrogen bonding interactions with similarly structured target (or template) molecules. In this work, an electrochemical method was used to optimize the synthetic self-assembly of poly(aniline-co-metanilic acid) and testosterone, forming testosterone-imprinted electronically conductive polymers (TIECPs) on sensing electrodes. The linear sensing range for testosterone was from 0.1 to $100 \mathrm{pg} / \mathrm{mL}$, and the limit of detection was as low as $\sim$ pM. Random urine samples were collected and diluted 1000-fold to measure testosterone concentration using the above TIECP sensors; results were compared with a commercial ARCHITECT ci 8200 system. The testosterone concentrations in the tested samples were in the range of $0.33 \pm 0.09$ to $9.13 \pm 1.33 \mathrm{ng} / \mathrm{mL}$. The mean accuracy of the TIECP-coated sensors was $90.3 \pm 7.0 \%$.
\end{abstract}

Keywords: testosterone; molecular imprinting; electronically conductive polymer; electrochemical sensing; urine

\section{Introduction}

For men beyond the age of 30, testosterone levels gradually decline with increasing age [1]. Some possible causes of low testosterone levels are testicular injury or infection [2], dysfunctional hormone excretion, medication, inflammation and chronic illness (such as chronic kidney failure [3], dysthymic disorder [4], alcoholism, hepatic cirrhosis [5] or obesity [6]). A homecare system, monitoring testosterone concentration, may offer important diagnostic benefits.

Molecularly imprinted polymers (MIPs) for measuring the concentration of hormones and metabolites have been produced in the last decade and used for optical sensing by surface plasmon resonance (SPR) to detect progesterone [7], cholesterol [7] and testosterone [7-10]. More traditional laboratory-based methods have also been used, such as: gas chromatography (GC) for measurement of anabolic steroids [11] and extraction steroids [12]; liquid chromatography (LC) for measurement of epitestosterone [13], testosterone [13-15], or other steroids [16]; capillary electrophoresis (EC) linked with mass spectrometry (MS) for testosterone [17], epitestosterone [17], urinary steroid hormones [18] and estrogenic endocrine disruptors [19]; diode-array 
detection (DAD) of steroids [20], progesterone [21] and testosterone [21] in human urine [11,17,20-23] or in goat milk [24]. The functional and crosslinking monomers that have been used in molecular imprinting include acrylamide [16], methacrylic acid (MAA) [7-11,13,15,17,20,21,24-28], trifluoromethacrylic acid (TFMAA) [13], 2-hydroxyethyl methacrylate (HEMA) [9,26], ethylvinylbenzene (EVB) [7], 2-vinylpyridine (2VP) [12], 4-vinylpyridine (4VP) [12,20,26], dopamine (DA) [14]; divinylbenzene (DVB) [7,13], ethylene glycol dimethacrylate (EGDMA) [8-11,16,17,20-24,26-28], trimethylolpropanetrimethacrylate (TRIM) [11,20,21], pentaerythritol triacrylate (PETRA) [22] and $5 \alpha$-androstane-3 $\alpha, 17 \beta$-dimethacryloxy ester (AnDMA) [13]. Synthetic functional monomers such as (1) 1-(4-vinylphenyl)-3-(3,5-bis(trifluromethyl)phenyl)urea (FM1) and 1-benzyl-3-vinyl-2,3-dihydro-1H-imidazolium bromide (FM2) have been used to isolate testosterone glucuronide [22] and (2) the bifunctional cross-linker N,O-bismethacryloylethanolamine (NOBE) have been synthesized to form patterned MIP structures to detect testosterone in buffer, urine and saliva using electrochemical impedance spectroscopy (EIS) [29]. A visible light-activated photo-iniferter agent, 4-cyano-4-[(dodecylsulfanyl- thiocarbonyl) sulfanyl]pentanoic acid (CDTPA), was employed for chain extension with poly(ethylene glycol methacrylate phosphate) brushes by reversible addition-fragmentation chain transfer (RAFT) polymerization [30]. In addition, the imprinting of other steroid hormones (e.g., $17 \beta$-estradiol) has been used for increasing the retention of testosterone in solid phase extraction [18]. A recent comparison of methods for testosterone determination reported limits of detection (LODs) in the range of $0.08-20.0 \mathrm{ng} / \mathrm{mL}$ [14]. The majority of techniques employed either SPR or chromatographic techniques; electrochemical methods, despite their advantages of low cost and flexibility, have not been reported for testosterone.

The use of conducting polymers in sensor-related technology [31] and electrochemically prepared MIPs have each been reviewed [32,33]. Polyaniline (PANI) derivatives can be electrochemically polymerized [34,35], chemically polymerized [36], and even simultaneously self-assembled/polymerized $[37,38]$ in aqueous solutions. PANI derivatives have attracted substantial scientific interest in recent decades owing to their favorable combination of characteristics, including: a more diverse structure and better thermal and radiation stability than polypyrrole; lower cost than polythiophene; ease of synthesis; and moderately high conductivity. They have, therefore, been used in a wide range of applications [39], such as micro-electronics, corrosion protection, battery electrodes, and sensors [40].

In this work, an electrochemical method was employed to optimize the synthetic self-assembly of poly(aniline-co-metanilic acid) and template molecules by coating on the sensing electrodes, to form testosterone-imprinted polymers (TIECPs). Generally, the polymerization of polyaniline needs to be carried out in an acidic environment. In this environment, it is often necessary to add an extra inorganic/organic acid as a dopant which provides hydrogen ions to dope the amine groups on polyaniline. The resulting doped polyaniline has moderately high conductivity, an important attribute for electrochemical sensing applications. In this study, aminobenezenesulfonic acid (metanilic acid) has a dual role as a reactive monomer (aminobenzene) and as a dopant (sulfonic acid group); metanilic acid was copolymerized with aniline monomer to obtain self-doped polyaniline films, eliminating the need for an extraneous acid. The TIECPs were characterized by their imprinting effectiveness $(\alpha)$, which is the ratio of current densities generated in the sensing of template molecules by imprinted and non-imprinted polymer-coated electrodes. The surface morphologies and electronic spectra of the TIECPs during self-assembly were obtained using a scanning electron microscope (SEM). Finally, random urine samples were collected, and their testosterone concentrations were measured using TIECP sensors. The experimental results were compared with results from a commercial ARCHITECT ci 8200 system to confirm the reliability. 


\section{Materials and Methods}

\subsection{Reagents}

Aniline (ANI, Merck, Darmstadt, Germany) was distilled under reduced pressure, and metanilic acid or $m$-aminobenzenesulfonic acid (MSAN, Acros Organics, Geel, Belgium) was purified by recrystallization twice from deionized (DI) water. Testosterone $(\geq 98.0 \%)$, progesterone $(\geq 99.0 \%)$, urea (minimum $\geq 98.0 \%$ ), creatinine (minimum $\geq 99.0 \%$ ), and ethanol were purchased from Sigma-Aldrich Co. (St. Louis, MO, USA). 17 $\beta$-Estradiol ( $\geq 98.0 \%$ ) was from Alfa-Aesar (Ward Hill, MA, USA). Ammonium peroxydisulfate (APS) used as the initiator was from Wako (Osaka, Japan). The ITO-coated glass substrates $\left(\sim 10 \Omega \cdot \mathrm{cm}^{-2}\right)$ were from Merck. Deionized water $(18.2 \mathrm{M} \Omega)$, produced by a PURELAB Ultra (ELGA, High Wycombe, UK), was used in the preparation of buffers and for rinse solutions. All chemicals were used as received unless otherwise mentioned.

\subsection{Synthesis and Characterization of Testosterone-imprinted Electronically Conductive Polymer (TIECP) films}

The synthetic procedure has been successfully used in our previous studies. The surface of an ITO electrode was sequentially cleaned by using isopropanol, acetone, and distilled water before polymerization [41,42]. Electrically conductive polymer films were assembled (polymerized) on ITO glass (Merck, $1 \times 1 \mathrm{~cm}^{2}$ ). Aniline (ANI) and $m$-aminobenzenesulfonic acid (MSAN) in mole ratios from $20-80 \%$ were dissolved in DI water, keeping the total amino group concentration at $57 \mathrm{mM}$. To make imprinted films, testosterone, employed as the template and target molecule in this study, was included at concentrations up to $100 \mu \mathrm{g} / \mathrm{mL}$. Initiator/oxidant (APS, $0.5 \%$ (w/w)) was then added to the ANI/MSAN mixture, and polymerization proceeded by immersion of the ITO electrode in the monomer mixture at $25{ }^{\circ} \mathrm{C}$. The APS acts as an oxidant resulting in copolymerization to form electron-conducting poly(aniline-co-metanilic acid) from the aqueous mixture of ANI and MSAN [38]. Finally, ethanol solution $(5 \% \mathrm{v} / \mathrm{v})$ was employed for the removal of target molecules.

\subsection{Electrochemical Characterization of TIECP-coated Electrodes}

The TIECP-coated electrode, counter electrode (Pt wire), and Ag/AgCl (Matsusada Precision, Japan) reference electrode were placed in a mixture solution including $20 \mu \mathrm{L}$ sample (e.g., testosterone, urea, creatinine, $17 \beta$-estradiol and progesterone) and $20 \mathrm{~mL} 125 \mathrm{mM} \mathrm{KCl}, 5 \mathrm{mM} \mathrm{K}{ }_{4} \mathrm{Fe}(\mathrm{CN})_{6}$ and $5 \mathrm{mM}$ $\mathrm{K}_{3} \mathrm{Fe}(\mathrm{CN})_{6}$ solution; the cyclic voltammetry of the electrochemical reactions was performed using a potentiostat (608-1A, CH Instruments, Inc., Austin, TX). The film thickness of the electroactive film can be directly quantitatively measured from the current density of the redox couple using the calibration curve between the current density and film thickness [41,42]. The potential was scanned from $-0.3 \mathrm{~V}$ to $0.8 \mathrm{~V}$ at a san rate of $0.1 \mathrm{~V} / \mathrm{s}[43,44]$ and the effects of target and interferent molecules (e.g., urea, creatinine, $17 \beta$-estradiol and progesterone) on the peak currents for the ferri-/ferrocyanide system were also recorded. TIECP films were freeze-dried before examination by a scanning electron microscope (Hitachi S4800, Hitachi High-Technologies Co., Tokyo, Japan), and atomic force microscopy (Solver P47H-PRO, NT-MDT Moscow, Russia) and a golden silicon cantilever (NSG01, NT-MDT).

\subsection{The Determination of Testosterone in Human Urine Samples}

Urine samples were collected from colleagues of the authors $4 \mathrm{~h}$ before the test, and diluted 1000 -fold with $125 \mathrm{mM} \mathrm{KCl}, 5 \mathrm{mM} \mathrm{K}_{4} \mathrm{Fe}(\mathrm{CN})_{6}$ and $5 \mathrm{mM} \mathrm{K}_{3} \mathrm{Fe}(\mathrm{CN})_{6}$ solution. The urine sample (1 $\mathrm{mL}$ ) was stored in an Eppendorf microcentrifuge tube at $4{ }^{\circ} \mathrm{C}$ and analyzed for testosterone with the ARCHITECT ci 8200 system (Abbott Laboratories, Abbott Park, Illinois, USA.). The Abbott Architect ci8200 analyzer was specifically designed to provide clinical chemistry and immunoassay testing, which combines immunoassay and clinical chemistry on one integrated platform and runs up to 200 immunoassay tests and up to 1200 clinical chemistry tests an hour. Please refer to the following website for further information: https://www.corelaboratory.abbott/int/en/offerings/brands/architect/architectci8200. 


\section{Results and Discussion}

To assess the performance of testosterone-imprinted electrically conductive polymers (TIECPs) and non-imprinted electrically conductive polymers (NIECPs), current density for the ferri-ferrocyanide redox couple was measured in the presence and absence of $10 \mathrm{pg} / \mathrm{mL}$ testosterone. The current density difference (with and without testosterone) is plotted in Figure 1, for both imprinted TIECPS and NIECPs, as a function of composition. As the mole ratio of ANI to MSAN was varied, the largest difference between the testosterone responses for TIECPs and for NIECPs was obtained at 50 mole \% aniline (a 1:1 composition). Interestingly, not only was the electrochemical response of imprinted electrodes maximized at this composition, but the response of non-imprinted electrodes was also minimized, as discussed below. For this composition, the current density differences were $60.70 \pm 5.37$ and $19.00 \pm 3.00 \mu \mathrm{A} / \mathrm{cm}^{2}$ for TIECPs and NIECPs, respectively. This corresponds to an imprinting effectiveness of slightly over 3 .

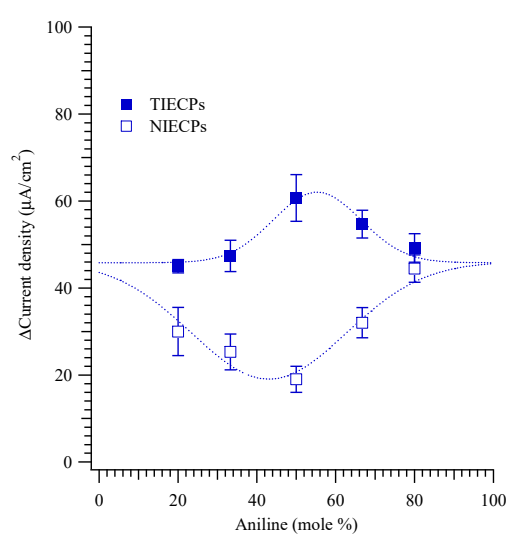

(a)

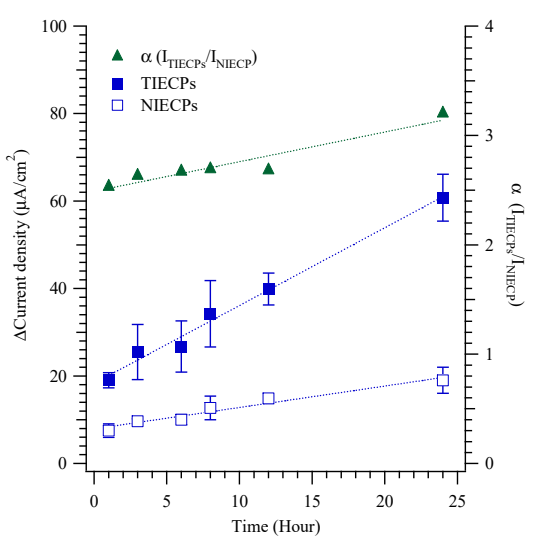

(b)

Figure 1. (a) Aniline concentration and changes in current density from cyclic voltammograms (CVs) in a solution of $20 \mathrm{mM}$ potassium ferricyanide $\left(\mathrm{K}_{3}\left[\mathrm{Fe}(\mathrm{CN})_{6}\right]\right), 20 \mathrm{mM}$ potassium ferrocyanide $\left(\mathrm{K}_{4}\left[\mathrm{Fe}(\mathrm{CN})_{6}\right]\right)$, and $0.5 \mathrm{M} \mathrm{KCl}$ with/without $10 \mathrm{pg} \mathrm{mL}^{-1}$ of testosterone on testosterone- and non-imprinted poly(aniline-co-metanilic acid)-coated electrodes, (b) imprinting effectiveness and current density versus polymerization duration of testosterone-imprinted and non-imprinted poly(aniline-co-metanilic acid).

In the ANI/MSAN copolymers, the sulfonic group is likely to bind to the secondary amine of aniline, and, thus, to be unavailable to bind testosterone. The effect should be most pronounced at equimolar ratios, and, in agreement with this expectation, the response of non-imprinted polymers to testosterone is minimized at equimolar composition. Interestingly, the response of the imprinted polymers increases at equimolar composition, in spite of the potential for reduced hydrogen bonding to the target. This may be caused by increased stiffness of the matrix, improving the binding site shape recognition, and the electrochemical reaction may occur only on the electrode surface. (In addition, of course, hydrogen bonding in the binding sites may still occur, as the hydrogen-bonded template will effectively sequester the sulfonic acid and prevent it from binding to ANI). Figure 1b shows that current density differences grow with increased polymerization time. Nonetheless, imprinting effectiveness varies only weakly with polymerization time.

Figure 2 displays scanning electron microscope images including bare ITO glass, TIECPs and NIECPs before and after template removal, as well as after binding with target molecules. In Figure 2a, the grain size of bare ITO glass was from $15 \mathrm{~nm}$ to $80 \mathrm{~nm}$; the morphologies and grain sizes of ITO were different from TIECPs and NIECPs thin films. Many poly(ANI-co-MSAN) particles and aggregates were observed on the surface of the sensing electrodes. The sizes of the aggregates were about 60-150 and 30-60 nm on the surface of TIECPs and NIECPs, respectively. SEM images of TIECP and NIECP electrodes rinsed in 5\% ethanol, shown in Figure 2d,e, reveal that the unbound poly(ANI-co-MSAN) particles on the surfaces had been cleared out. Based on the SEM images, the surface morphologies 
of the TIECP and NIECP thin films following readsorption of $10 \mathrm{pg} / \mathrm{mL}$ of testosterone are less rough after readsorption (compare Figure $2 \mathrm{f}, \mathrm{g}$ to Figure $2 \mathrm{~d}$,e respectively), when the cavities on the poly(ANI-co-MSAN) particle surface were refilled with the target molecules. The washed, imprinted films show considerable surface roughness, presumably owing to the presence of numerous binding sites or cavities. Further details of the surface morphology of TIECPs, determined by AFM, are shown in Figure 3; the size of polymer particles agreed with SEM images. The average surface roughness increased from $3.3 \mathrm{~nm}$ to $4.8 \mathrm{~nm}$ when template was removed, and then decreased to $3.4 \mathrm{~nm}$ upon rebinding of the target molecules.

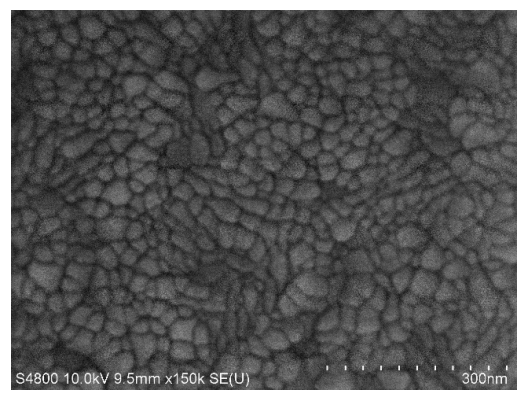

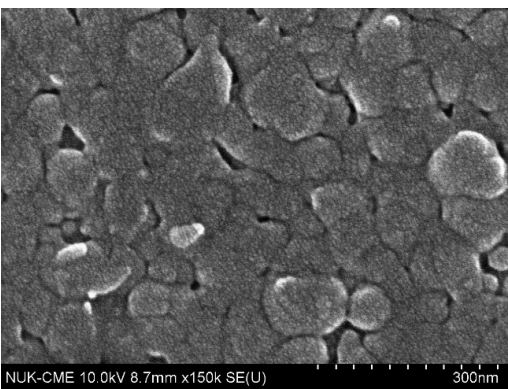

(b)

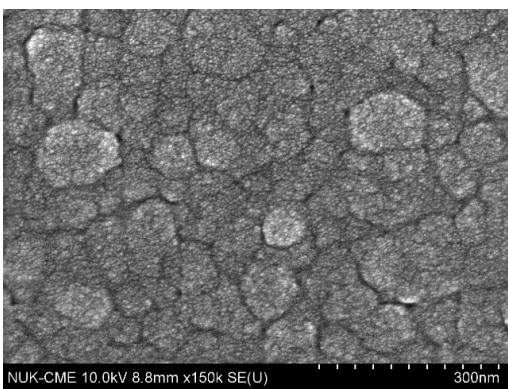

(d)

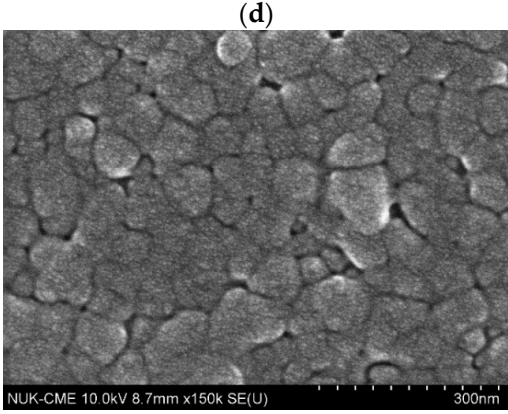

(f)

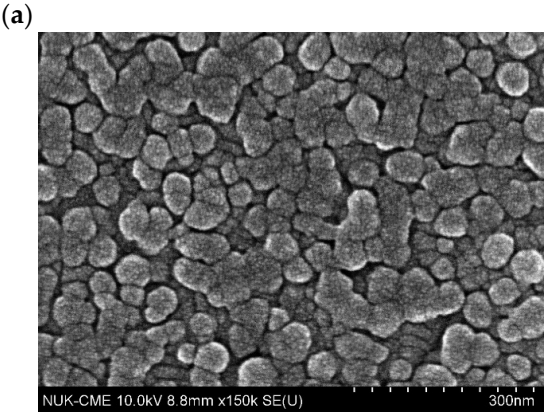

(c)

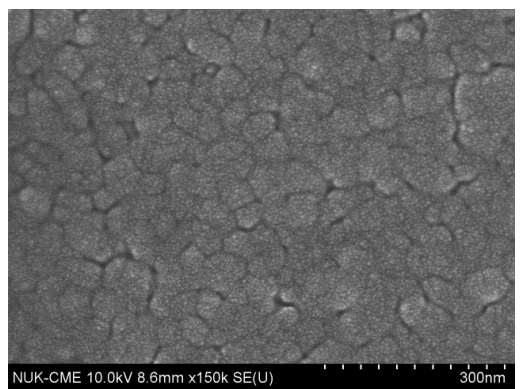

(e)

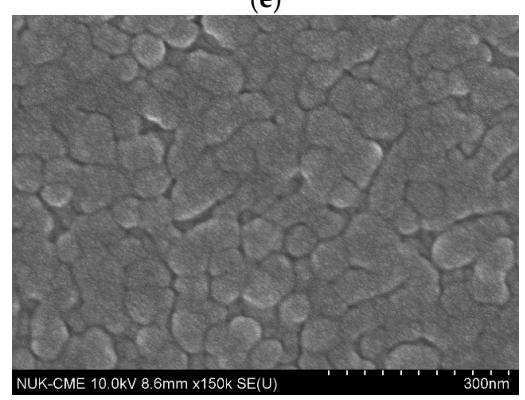

(g)

Figure 2. Scanning electronic microscopy images. (a) bare ITO glass; (b-g) testosterone-imprinted (left) and non-imprinted (right) poly(aniline-co-metanilic acid) containing 50 mole $\%$ of aniline: $(\mathbf{b}, \mathbf{c})$ before washing; (d,e) after washing; (f,g) after washing (template removed). The washed, imprinted films show considerable surface roughness, presumably owing to the presence of numerous binding sites or cavities. 
Cyclic voltammetric sensing of testosterone at concentrations of 0.01 to $5000 \mathrm{pg} / \mathrm{mL}$ was conducted using the TIECP and NIECP-coated electrodes, as presented in Figure $4 \mathrm{a}, \mathrm{b}$. The $\mathrm{pH}$ value was nearly constant at the different concentrations of testosterone. The maximum current densities of MIPs and NIECPs electrodes were ca. 1200 and $1000 \mu \mathrm{A} / \mathrm{cm}^{2}$, respectively. The electrochemical current densities were approximately 30-fold higher than our earlier work on MIPs using imprinted poly(ethylene-co-vinyl alcohol) (EVAL). (EVAL has been successfully used to measure small molecules, such as creatinine and urea [43]).

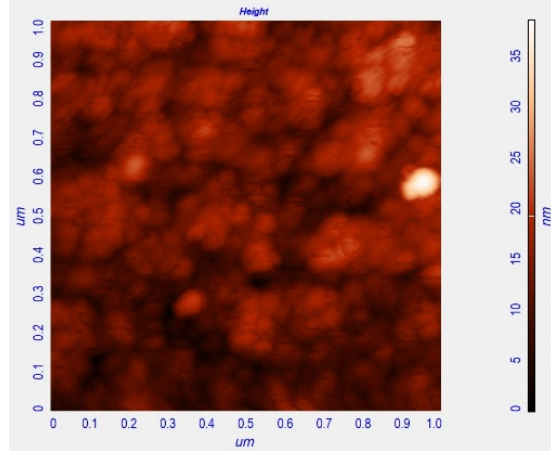

(a)

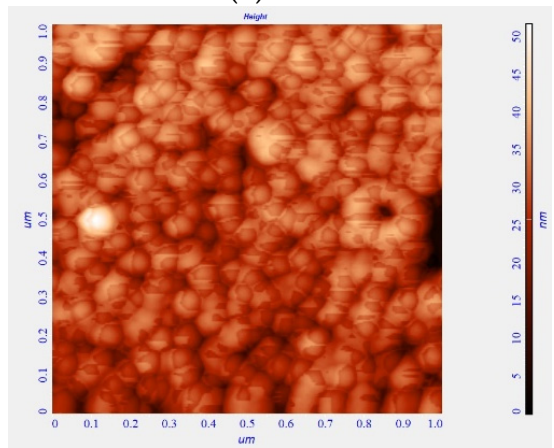

(c)

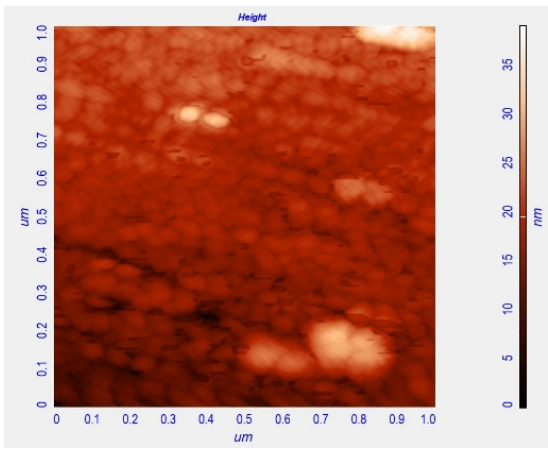

(e)

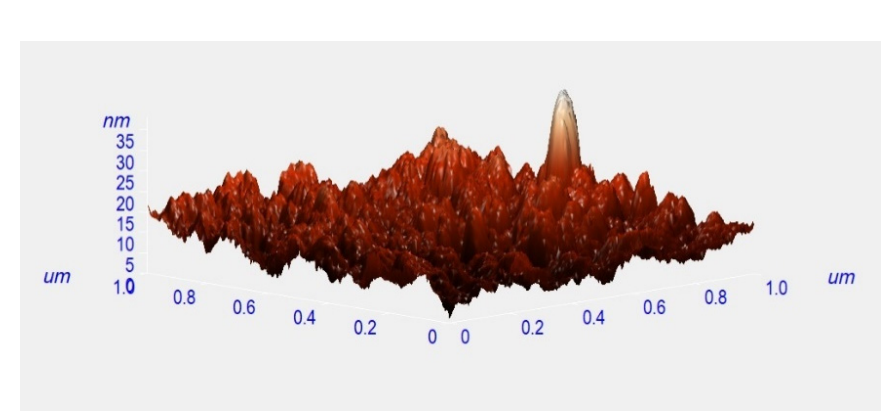

(b)

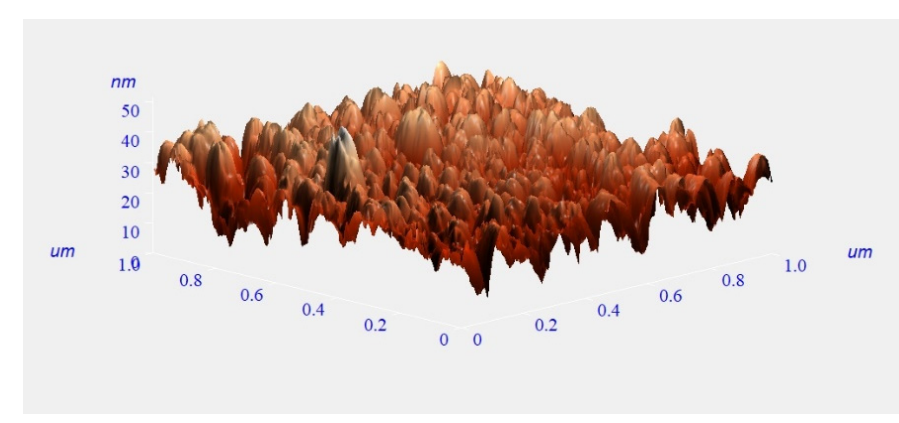

(d)

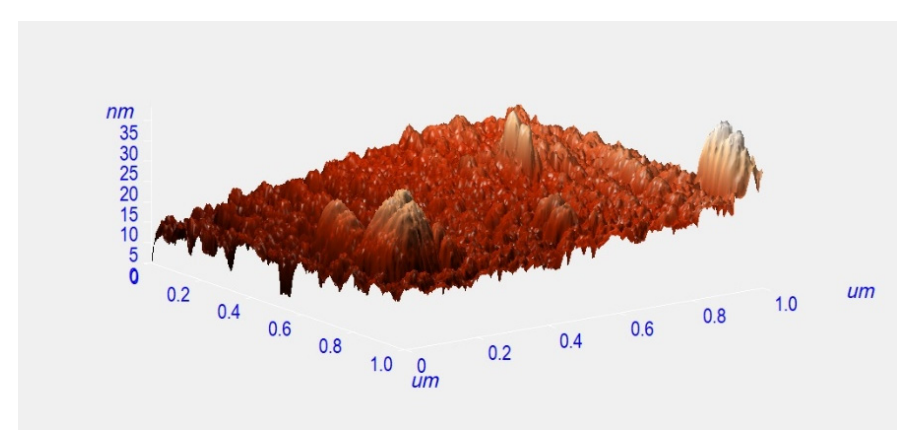

(f)

Figure 3. AFM images of a TIECP-coated electrode $(\mathbf{a}, \mathbf{b})$ before, $(\mathbf{c}, \mathbf{d})$ after template removal and $(\mathbf{e}, \mathbf{f})$ rebinding of the target molecules. (left) Height shown as intensity; (right) 3D representation (height exaggerated relative to horizontal scale.).

Figure 5a shows the changes in oxidation-peak current density for a range of testosterone (mass) concentrations, for both imprinted and non-imprinted polymeric sensors; also shown is the $\mathrm{pH}$ of the samples, which all fell between $6.12 \pm 0.05$ to $6.07 \pm 0.02$ for testosterone mass concentrations from 0 to $500 \mathrm{pg} / \mathrm{mL}$. Thus, the mass concentration of testosterone had essentially no effect on the $\mathrm{pH}$ value of these buffered solutions. 


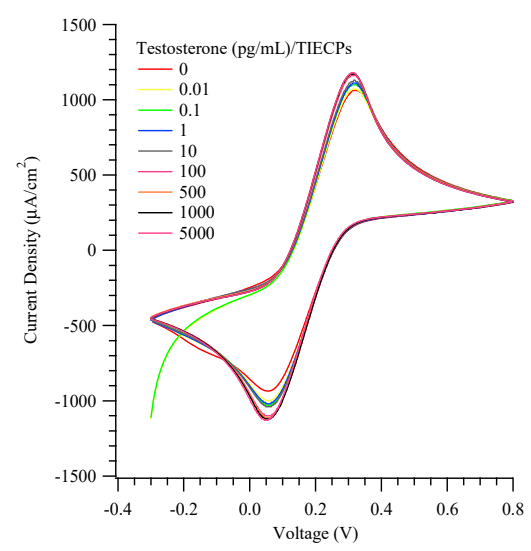

(a)

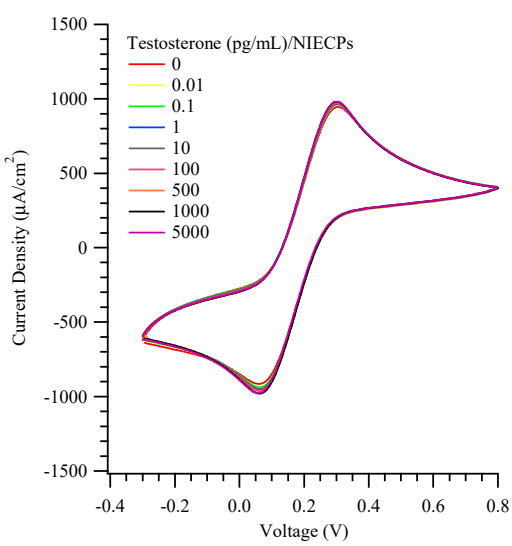

(b)

Figure 4. Cyclic voltammograms of various target concentrations on (a) testosterone- (TIECPs) and (b) non-imprinted poly(aniline-co-metanilic acid) (NIECPs) coated electrodes.

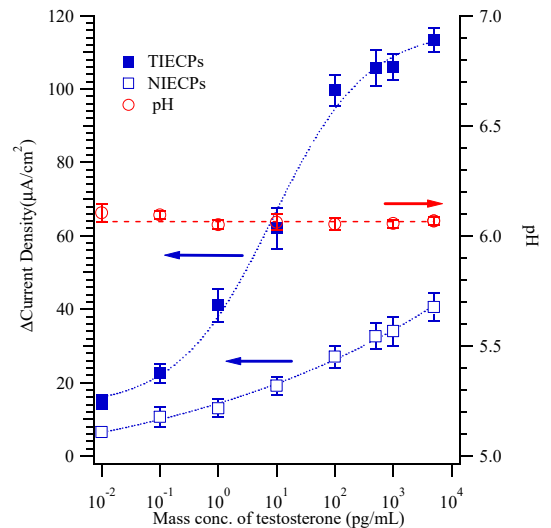

(a)

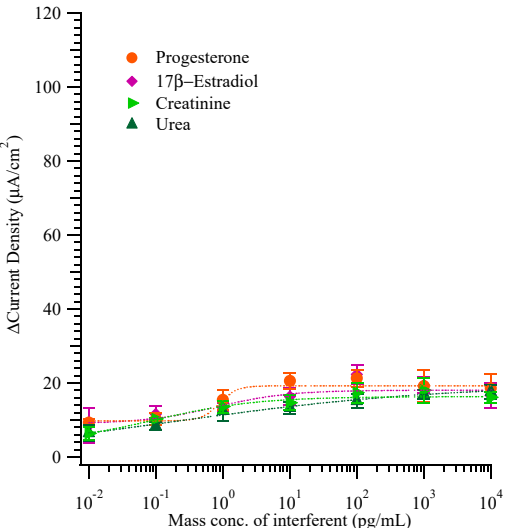

(b)

Figure 5. (a) The calibration curve of oxidation-peak current density and $\mathrm{pH}$ value from CVs against mass concentrations of testosterone on molecularly and non-imprinted poly(aniline-co-metanilic acid) based sensors. (b) The effect of the interferents (e.g., 17 $\beta$-estradiol (diamonds), progesterone (circles), urea (triangles), and creatinine (right triangles)) on peak current response was tested and is shown $(n>3)$.

Figure $5 \mathrm{a}$ also shows that the useful linear dynamic range is 0.1 to $100 \mathrm{pg} / \mathrm{mL}$ for testosterone, with the signal beginning to saturate at the higher concentration. We compare these results to other testosterone detection methods: micro-patterned MIPs on functionalized diamond-coated substrates were reported to show linearity from 0.5 to $20 \mathrm{nM}$ testosterone [29]; reflectance spectra of TIECPs films showed a shift of the Bragg diffraction peak that correlated with testosterone concentration in the range 5-100 ng/mL [15]. Thus, the electrochemical approach presented here is highly sensitive.

Figure $5 \mathrm{~b}$ shows that the current densities caused by potential interferents found in real urine samples (including $17 \beta$-estradiol, progesterone, urea, and creatinine) were less than $20 \mu \mathrm{A} / \mathrm{cm}^{2}$, quite similar to the current density caused by testosterone on non-imprinted sensors. Thus, the testosterone-imprinted poly(ANI-co-MSAN) film is effectively non-imprinted for these potential interferents. The selectivity of MIPs that were prepared by polymerization in this study exceeded that achieved in our previous work based on phase inversion [32]; for example, the 5-fold preference for testosterone over other interferents (in this work), vs. about a 2 -fold preference for urea over creatinine in [32]. 
Finally, Table 1 summarizes analyses of random urine samples performed by using the ARCHITECT ci 8200 system. The concentrations of testosterone in the samples fell in the range of $0.33 \pm 0.09$ to $9.13 \pm 1.33 \mathrm{ng} / \mathrm{mL}$. The current deviations measured by the TIECP sensor in at least three urine samples ranged from $27.35 \pm 1.15$ to $65.15 \pm 2.95 \mu \mathrm{A} / \mathrm{cm}^{2}$ corresponding to concentrations of $0.28 \pm 0.07$ to $8.99 \pm 2.68 \mathrm{ng} / \mathrm{mL}$ (standard deviations of at least three individual measurements). The mean accuracy of TIECPs-coated sensors was $90.3 \pm 7.0 \%$. Note that the accuracy was slightly lower, approximately $80-85 \%$, when the testosterone concentration in urine was less than about $2.0 \mathrm{ng} / \mathrm{mL}$.

Table 1. Comparison of real sample measurement by ARCHITECT ci 8200 system and the TIECP sensors.

\begin{tabular}{|c|c|c|c|c|}
\hline \multirow[b]{2}{*}{ Sample No. } & \multirow{2}{*}{$\begin{array}{c}\text { ARCHITECT ci } 8200 \text { System } \\
\text { Testosterone }(\mathrm{ng} / \mathrm{mL})\end{array}$} & \multicolumn{2}{|c|}{ TIECP Sensors } & \multirow[b]{2}{*}{ Accuracy (\%) } \\
\hline & & $\begin{array}{l}\Delta \text { Current } \\
\left(\mu \mathrm{A} / \mathrm{cm}^{2}\right)\end{array}$ & $\begin{array}{l}\text { Avg. conc. } \\
\text { (ng/mL) }\end{array}$ & \\
\hline 1 & $0.79 \pm 0.02$ & $33.85 \pm 0.25$ & $0.64 \pm 0.03$ & 81.0 \\
\hline 2 & $1.51 \pm 0.08$ & $40.65 \pm 0.75$ & $1.28 \pm 0.13$ & 84.8 \\
\hline 3 & $2.32 \pm 0.01$ & $47.10 \pm 1.90$ & $2.27 \pm 0.50$ & 97.8 \\
\hline 4 & $0.33 \pm 0.09$ & $27.35 \pm 1.15$ & $0.28 \pm 0.07$ & 84.8 \\
\hline 5 & $3.04 \pm 0.18$ & $50.05 \pm 1.95$ & $2.88 \pm 0.62$ & 94.7 \\
\hline 6 & $9.13 \pm 1.33$ & $65.15 \pm 2.95$ & $8.99 \pm 2.68$ & 98.5 \\
\hline
\end{tabular}

\section{Conclusions}

Monomers bearing an aromatic ring may have a greater tendency than other aliphatic structures to exhibit hydrogen bonding interactions with target (or template) molecules [32], making them attractive for use in molecularly imprinted polymer applications. Our experiments showed these materials are especially suitable for the preparation of molecularly imprinted polymers for steroid hormones, by demonstrating the specific recognition of testosterone by imprinted ANI/MSAN copolymers. This work also demonstrated the importance of monomer ratio in creating films with specific and selective recognition, and detailed the distinctive surface morphologies of both imprinted and non-imprinted films for effective and accurate electrochemical detection of testosterone in urine.

Author Contributions: Conceptualization: D.O., J.L.T., C.-H.Y., and M.-H.L.; data curation: K.-H.L., H.-Z.G. and M.-H.L.; supervision: C.-H.Y. and M.-H.L.; writing—original draft: K.-H.L., C.-H.Y. and M.-H.L.; writing-review and editing: D.O., J.L.T., C.-H.Y. and M.-H.L. All authors have read and agreed to the published version of the manuscript.

Funding: This research was funded by the Ministry of Science and Technology of ROC under Contract nos. MOST 104-2220-E-390-001, MOST 105-2221-E-390-026 and MOST 105-2918-I-390-001.

Acknowledgments: We thank Hung-Yin Lin for his support and encouragement throughout this work.

Conflicts of Interest: The authors declare no conflict of interest.

\section{References}

1. Feldman, H.A.; Longcope, C.; Derby, C.A.; Johannes, C.B.; Araujo, A.B.; Coviello, A.D.; Bremner, W.J.; McKinlay, J.B. Age trends in the level of serum testosterone and other hormones in middle-aged men: Longitudinal results from the massachusetts male aging study. J. Clin. Endocrinol. Metab. 2002, 87, 589-598. [CrossRef] [PubMed]

2. Bhasin, S.; Storer, T.W.; Javanbakht, M.; Berman, N.; Yarasheski, K.E.; Phillips, J.; Dike, M.; Indrani, S.-H.; Shen, R.; Hays, R.D.; et al. Testosterone replacement and resistance exercise in hiv-infected men with weight loss and low testosterone levels. JAMA 2000, 283, 763-770. [CrossRef]

3. Carrero, J.J.; Qureshi, A.R.; Parini, P.; Arver, S.; Lindholm, B.; Bárány, P.; Heimbürger, O.; Stenvinkel, P. Low serum testosterone increases mortality risk among male dialysis patients. J. Am. Soc. Nephrol. 2009, 20, 613-620. [CrossRef] [PubMed]

4. Seidman, S.N.; Araujo, A.B.; Roose, S.P.; Devanand, D.P.; Xie, S.; Cooper, T.B.; McKinlay, J.B. Low testosterone levels in elderly men with dysthymic disorder. Am. J. Psychiatry 2002, 159, 456-459. [CrossRef] [PubMed] 
5. Baker, H.; Burger, H.; De Kretser, D.; Dulmanis, A.; Hudson, B.; O'Connor, S.; Paulsen, C.; Purcell, N.; Rennie, G.; Seah, C. A study of the endocrine manifestations of hepatic cirrhosis. QJM 1976, 45, 145-178. [PubMed]

6. Diaz-Arjonilla, M.; Schwarcz, M.; Swerdloff, R.S.; Wang, C. Obesity, low testosterone levels and erectile dysfunction. Int. J. Impot. Res. 2008, 21, 89-98. [CrossRef] [PubMed]

7. Huang, S.-C.; Lee, G.-B.; Chien, F.-C.; Chen, S.-J.; Chen, W.-J.; Yang, M.-C. A microfluidic system with integrated molecular imprinting polymer films for surface plasmon resonance detection. J. Micromech. Microeng. 2006, 16, 1251. [CrossRef]

8. Wei, Q.Q.; Wei, T.X. A novel method to prepare spr sensor chips based on photografting molecularly imprinted polymer. Chin. Chem. Lett. 2011, 22, 721-724. [CrossRef]

9. Zhang, Q.; Jing, L.; Zhang, J.; Ren, Y.; Wang, Y.; Wang, Y.; Wei, T.; Liedberg, B. Surface plasmon resonance sensor for femtomolar detection of testosterone with water-compatible macroporous molecularly imprinted film. Anal. Biochem. 2014, 463, 7-14. [CrossRef]

10. Tan, Y.; Jing, L.; Ding, Y.; Wei, T. A novel double-layer molecularly imprinted polymer film based surface plasmon resonance for determination of testosterone in aqueous media. Appl. Surf. Sci. 2015, 342, 84-91. [CrossRef]

11. Qiu, L.; Liu, W.; Huang, M.; Zhang, L. Preparation and application of solid-phase microextraction fiber based on molecularly imprinted polymer for determination of anabolic steroids in complicated samples. J. Chromatogr. A 2010, 1217, 7461-7470. [CrossRef] [PubMed]

12. Zulfiqar, A.; Morgan, G.; Turner, N.W. Detection of multiple steroidal compounds in synthetic urine using comprehensive gas chromatography-mass spectrometry (gc[times]gc-ms) combined with a molecularly imprinted polymer clean-up protocol. Analyst 2014, 139, 4955-4963. [CrossRef] [PubMed]

13. Gavrilović, I.; Mitchell, K.; Brailsford, A.D.; Cowan, D.A.; Kicman, A.T.; Ansell, R.J. A molecularly imprinted receptor for separation of testosterone and epitestosterone, based on a steroidal cross-linker. Steroids 2011, 76, 478-483. [CrossRef] [PubMed]

14. Tang, X.; Liu, W.; Chen, J.; Jia, J.; Ma, Z.; Shi, Q.; Gao, Y.; Wang, X.; Xu, S.; Wang, K.; et al. Preparation and evaluation of polydopamine imprinting layer coated multi-walled carbon nanotubes for the determination of testosterone in prostate cancer lncap cells. Anal. Methods 2015, 7, 8326-8334. [CrossRef]

15. Kadhem, A.; Xiang, S.; Nagel, S.; Lin, C.-H.; Fidalgo de Cortalezzi, M. Photonic molecularly imprinted polymer film for the detection of testosterone in aqueous samples. Polymers 2018, 10, 349. [CrossRef]

16. Kopperi, M.; Riekkola, M.-L. Non-targeted evaluation of selectivity of water-compatible class selective adsorbents for the analysis of steroids in wastewater. Anal. Chim. Acta 2016, 920, 47-53. [CrossRef]

17. Tse Sum Bui, B.; Merlier, F.; Haupt, K. Toward the use of a molecularly imprinted polymer in doping analysis: Selective preconcentration and analysis of testosterone and epitestosterone in human urine. Anal. Chem. 2010, 82, 4420-4427. [CrossRef]

18. Doué, M.; Bichon, E.; Dervilly-Pinel, G.; Pichon, V.; Chapuis-Hugon, F.; Lesellier, E.; West, C.; Monteau, F.; Le Bizec, B. Molecularly imprinted polymer applied to the selective isolation of urinary steroid hormones: An efficient tool in the control of natural steroid hormones abuse in cattle. J. Chromatogr. A 2012, 1270, 51-61. [CrossRef]

19. Bousoumah, R.; Antignac, J.P.; Camel, V.; Grimaldi, M.; Balaguer, P.; Courant, F.; Bichon, E.; Morvan, M.-L.; Le Bizec, B. Development of a molecular recognition based approach for multi-residue extraction of estrogenic endocrine disruptors from biological fluids coupled to liquid chromatography-tandem mass spectrometry measurement. Anal. Bioanal. Chem. 2015, 407, 8713-8723. [CrossRef]

20. Gadzała-Kopciuch, R.; Ričanyová, J.; Buszewski, B. Isolation and detection of steroids from human urine by molecularly imprinted solid-phase extraction and liquid chromatography. J. Chromatogr. B 2009, 877, 1177-1184. [CrossRef]

21. Ričanyová, J.; Gadzała-Kopciuch, R.; Reiffova, K.; Bazel, Y.; Buszewski, B. Molecularly imprinted adsorbents for preconcentration and isolation of progesterone and testosterone by solid phase extraction combined with hplc. Adsorption 2010, 16, 473-483. [CrossRef]

22. Ambrosini, S.; Shinde, S.; De Lorenzi, E.; Sellergren, B. Glucuronide directed molecularly imprinted solid-phase extraction: Isolation of testosterone glucuronide from its parent drug in urine. Analyst 2012, 137, 249-254. [CrossRef] [PubMed] 
23. Augustine, A.; Mathew, B. Synthesis of carbon nanotube incorporated molecular imprinted polymer with binding affinity towards testosterone. ISRN Polym. Sci. 2014, 2014, 7. [CrossRef]

24. González-Sálamo, J.; Socas-Rodríguez, B.; Hernández-Borges, J.; del Mar Afonso, M.; Rodríguez-Delgado, M.Á. Evaluation of two molecularly imprinted polymers for the solid-phase extraction of natural, synthetic and mycoestrogens from environmental water samples before liquid chromatography with mass spectrometry. J. Sep. Sci. 2015, 38, 2692-2699. [CrossRef] [PubMed]

25. Sanglar, C.; Jansen, T.; Silaghi, M.C.; Mernier, J.; Mignon, P.; Chermette, H. Study of prepolymerization complex formation in the synthesis of steroid-based molecularly imprinted polymers. Anal. Chem. 2012, 84, 4481-4488. [CrossRef]

26. Panagiotopoulou, M.; Beyazit, S.; Nestora, S.; Haupt, K.; Tse Sum Bui, B. Initiator-free synthesis of molecularly imprinted polymers by polymerization of self-initiated monomers. Polymer 2015, 66, 43-51. [CrossRef]

27. Adali-Kaya, Z.; TseSum Bui, B.; Falcimaigne-Cordin, A.; Haupt, K. Molecularly imprinted polymer nanomaterials and nanocomposites: Atom-transfer radical polymerization with acidic monomers. Angew. Chem. Int. Ed. 2015, 54, 5192-5195. [CrossRef]

28. Chen, Y.; Liu, Y.; Shen, X.; Chang, Z.; Tang, L.; Dong, W.-F.; Li, M.; He, J.-J. Ultrasensitive detection of testosterone using microring resonator with molecularly imprinted polymers. Sensors 2015, 15, 31558-31565. [CrossRef]

29. Kellens, E.; Bové, H.; Vandenryt, T.; Lambrichts, J.; Dekens, J.; Drijkoningen, S.; D’Haen, J.; De Ceuninck, W.; Thoelen, R.; Junkers, T. Micro-patterned molecularly imprinted polymer structures on functionalized diamond-coated substrates for testosterone detection. Biosens. Bioelectron. 2018, 118, 58-65. [CrossRef]

30. Garcia-Soto, M.J.; Haupt, K.; Gonzato, C. Synthesis of molecularly imprinted polymers by photo-iniferter polymerization under visible light. Polym. Chem. 2017, 8, 4830-4834. [CrossRef]

31. Janata, J.; Josowicz, M. Conducting polymers in electronic chemical sensors. Nat. Mater. 2003, 2, 19-24. [CrossRef] [PubMed]

32. Sharma, P.S.; Pietrzyk-Le, A.; D'Souza, F.; Kutner, W. Electrochemically synthesized polymers in molecular imprinting for chemical sensing. Anal. Bioanal. Chem. 2012, 402, 3177-3204. [CrossRef]

33. Malitesta, C.; Mazzotta, E.; Picca, R.A.; Poma, A.; Chianella, I.; Piletsky, S.A. Mip sensors-the electrochemical approach. Anal. Bioanal. Chem. 2012, 402, 1827-1846. [CrossRef] [PubMed]

34. Yang, C.H.; Wen, T.C. Polyaniline derivative with external and internal doping via electrochemical copolymerization of aniline and 2,5-diaminobenzenesulfonic acid on iro2-coated titanium electrode. J. Electrochem. Soc. 1994, 141, 2624-2632. [CrossRef]

35. Lee, M.-H.; Thomas, J.L.; Su, Z.-L.; Zhang, Z.-X.; Lin, C.-Y.; Huang, Y.-S.; Yang, C.-H.; Lin, H.-Y. Doping of transition metal dichalcogenides in molecularly imprinted conductive polymers for the ultrasensitive determination of 17 $\beta$-estradiol in eel serum. Biosens. Bioelectron. 2019, 150, 111901. [CrossRef] [PubMed]

36. Yang, C.-H.; Chih, Y.-K.; Cheng, H.-E.; Chen, C.-H. Nanofibers of self-doped polyaniline. Polymer 2005, 46, 10688-10698. [CrossRef]

37. Yang, C.-H.; Huang, L.-R.; Chih, Y.-K.; Chung, S.-L. Simultaneous molecular-layer assembly and copolymerization of aniline and o-aminobenzenesulfonic acid for application in electrochromic devices. J. Phys. Chem. C 2007, 111, 3786-3794. [CrossRef]

38. Lee, M.-H.; O’Hare, D.; Guo, H.-Z.; Yang, C.-H.; Lin, H.-Y. Electrochemical sensing of urinary progesterone with molecularly imprinted poly (aniline-co-metanilic acid) s. J. Mater. Chem. B 2016, 4, 3782-3787. [CrossRef]

39. Syed, A.A.; Dinesan, M.K. Review: Polyaniline-A novel polymeric material. Talanta 1991, 38, 815-837. [CrossRef]

40. Anand, M.S.; Sruthi, P.U.; Banshi, D.G. A localized and propagating spr, and molecular imprinting based fiber-optic ascorbic acid sensor using an in situ polymerized polyaniline-ag nanocomposite. Nanotechnology 2016, 27, 345501.

41. Yang, C.-H.; Wang, T.-L.; Shieh, Y.-T. Molecular assembled crosslinked self-doped polyaniline nano-thin films in application of electrochromic devices. Electrochem. Commun. 2009, 11, 335-338. [CrossRef]

42. Yang, C.-H.; Huang, L.-R.; Chih, Y.-K.; Lin, W.-C.; Liu, F.-J.; Wang, T.-L. Molecular assembled self-doped polyaniline copolymer ultra-thin films. Polymer 2007, 48, 3237-3247. [CrossRef] 
43. Huang, C.-Y.; Tsai, T.-C.; Thomas, J.L.; Lee, M.-H.; Liu, B.-D.; Lin, H.-Y. Urinalysis with molecularly imprinted poly(ethylene-co-vinyl alcohol) potentiostat sensors. Biosens. Bioelectron. 2009, 24, 2611-2617. [CrossRef] [PubMed]

44. Huang, C.-Y.; O’Hare, D.; Chao, I.J.; Wei, H.-W.; Liang, Y.-F.; Liu, B.-D.; Lee, M.-H.; Lin, H.-Y. Integrated potentiostat for electrochemical sensing of urinary 3-hydroxyanthranilic acid with molecularly imprinted poly(ethylene-co-vinyl alcohol). Biosens. Bioelectron. 2015, 67, 208-213. [CrossRef] 